\title{
La hacienda de Santo Tomás del Monte en Churriana (Málaga). De jardín conventual a palacio barroco
}

\author{
José Miguel Morales Folguera \\ Universidad de Málaga \\ jmmorales@uma.es
}

Fray Alonso de Santo Tomás [1], obispo de Málaga e hijo natural de Felipe IV, había adquirido la propiedad de la hacienda de El Retiro (Churriana, Málaga) en el año 1669, poniéndole el nombre de Santo Thomás del Monte, que unía su propio nombre con el del palacio que Salomón construyó para su recreo, diversión y amenidad junto a Jerusalén, al que llamó Monte del Líbano (Morales, 1996: 34). En realidad, el nombre del palacio, que Salomón construyó durante trece años era Bosque del Líbano y constaba de varias edificaciones. El conjunto central se denominaba Bosque del Líbano, y los adyacentes Pórtico del Líbano, Pórtico de la Justicia, y la residencia privada de Salomón y de la hija del faraón. Se llamaba Bosque del Líbano por la profusión de columnas de cedro de su gran sala hipóstila, que medía 50 x 25 m y estaba dividida en cinco naves por cuatro hileras de columnas. En el Pórtico de la Justicia, llamado también Pórtico del Trono, Salomón administraba justicia. Se hallaba al sur del monte Moriah, formando parte del barrio real (Peters, 1985: 15-16).

Durante los 23 años que le duró la posesión al obispo la primitiva casa fuerte se va a transformar en una finca agrícola, en la que no faltaban los típicos jardines conventuales. Estos jardines corresponden al denominado Jardín Huerto, que tiene una morfología que recuerda tanto a los huertos de los monasterios medievales como al Hortus conclusus y al Jardín Secreto del Renacimiento. Está formado por una planta rectangular dividida en cuatro sectores por la existencia de paseos, que se cruzan en el centro, donde se halla la denominada Fuente de la Batalla [2], rehundida en el suelo con forma octogonal y recubierta de azulejos vidriados polícromos. En el sector meridional de su brazo más largo hay una gruta con una fuente, alimentada por un estanque colocado encima (Morales, 1994b: 221-226), y la entrada está formada por un arco recubierto

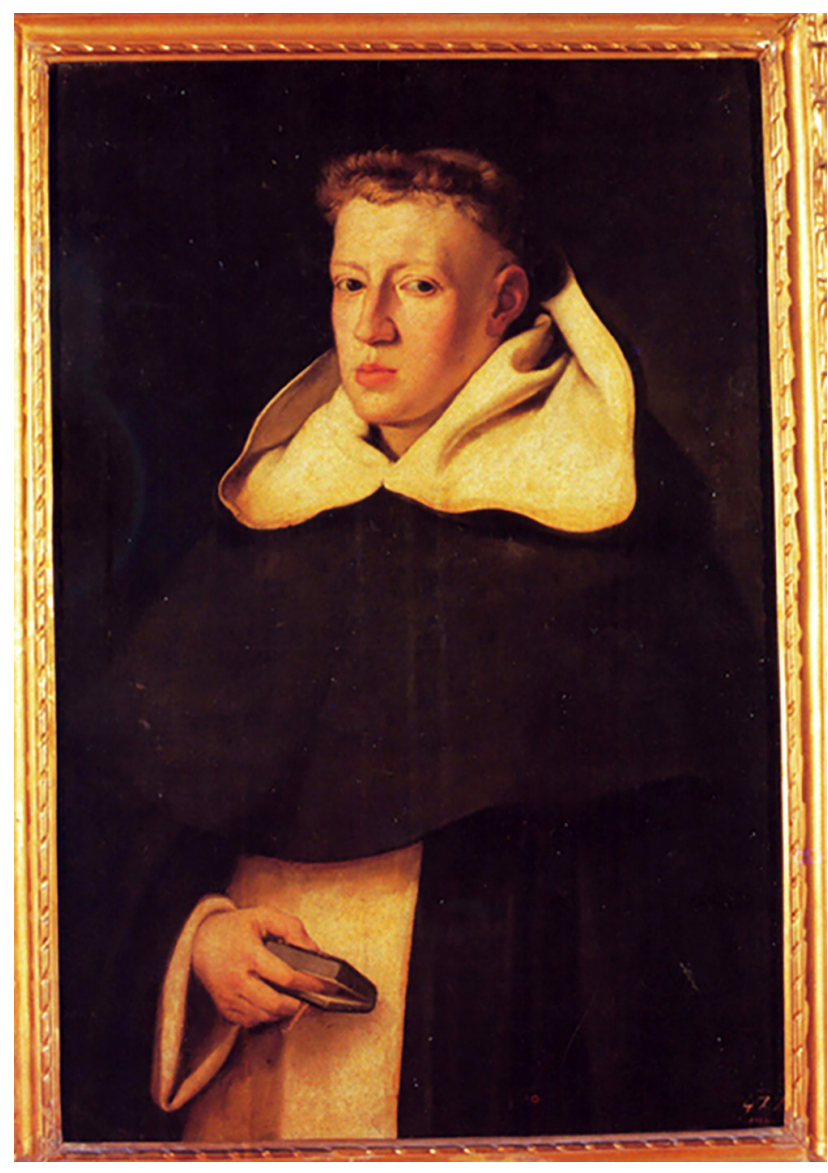

1. Juan Bautista Maíno, retrato de Fray Alonso de Santo Tomás, 16481649. Óleo sobre lienzo. Museo Nacional de Arte de Cataluña

con conchas marinas, que le da el aspecto de las grutas renacentistas [3].

El día 30 de julio de 1692 falleció en su convento de Málaga el obispo fray Alonso de Santo Tomás, por lo que en virtud de la "escritura de donación inter vivos» se dio posesión judicial al convento de Santo Domingo de la ha- 


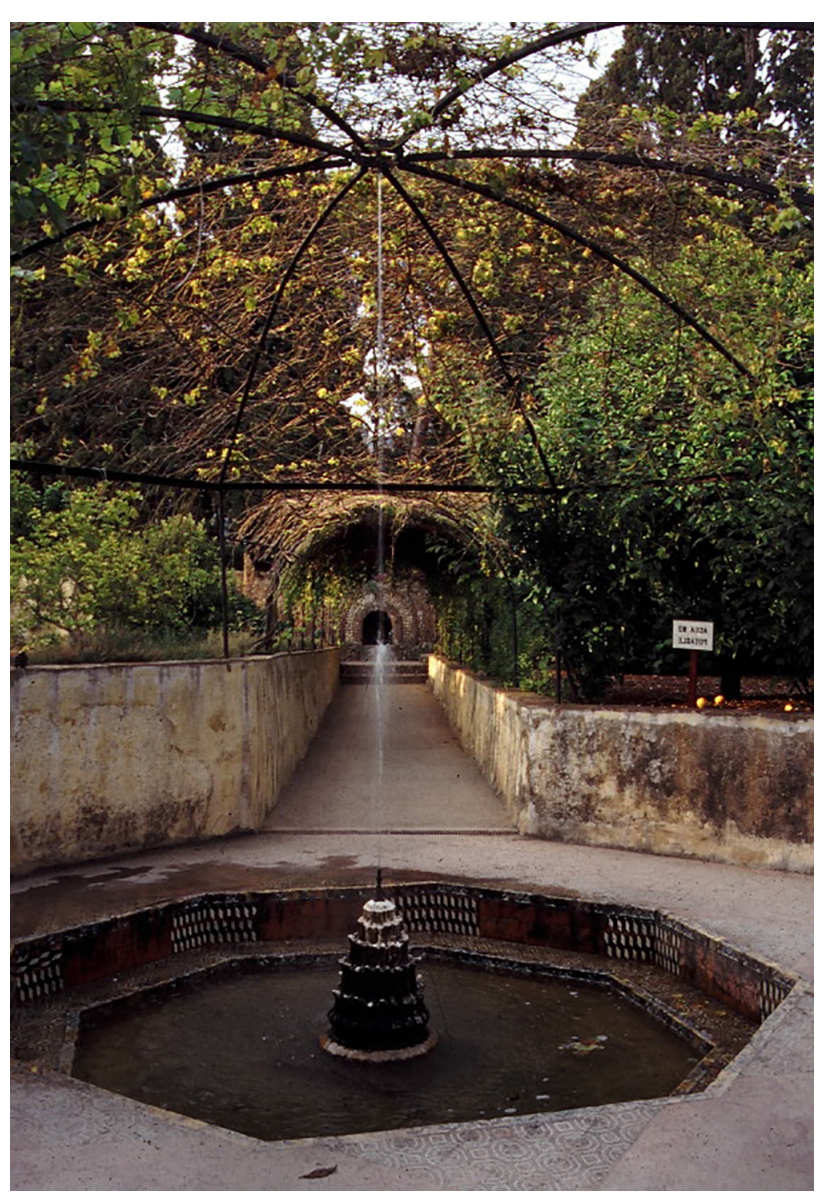

2. Fuente de la Batalla en el Jardín Huerto

3. Arco de entrada al Jardín Huerto

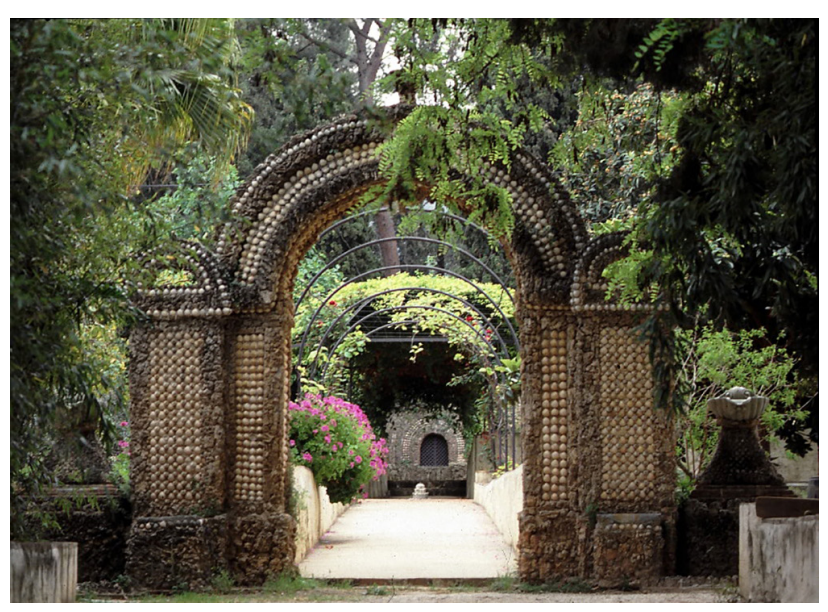

cienda de Santo Thomás del Monte. Una de las motivaciones que se alega en el pleito es "que se eternize en Santo Thomas del Monte la memoria de su llustrissima, y no se borre con estatuas profanas, que como ya tiene ideado quien ha comprado el Spolio, se coloquen en sus jardines y fuentes, sino sea la Estatua, el nombre de tan Eminente Prelado» ${ }^{1}$.

Efectivamente, poco después de la muerte del obispo la escritura de donación fue impugnada tanto por el defensor de los bienes del expolio como por la Cámara Apostólica. Esta impugnación se basaba en la norma que impedía que las posesiones privadas pasaran a entidades religiosas, ya que tenían que ser vendidas mediante una subasta pública, revirtiendo los beneficios a la Hacienda Real. Mediante este expolio la propiedad de la hacienda de Santo Tomás del Monte fue adquirida poco después por el primer conde de Buenavista, José Guerrero Chavarino. Su proyecto era transformar el primitivo huerto monástico en un jardín renacentista y barroco, siguiendo los modelos italianos, adornando las plazoletas y los paseos con fuentes y esculturas mitológicas de mármol adquiridas en Génova, de donde era originaria la familia de los condes de Buenavista.

En el año 1693 el convento de Santo Domingo entabló un pleito para recuperar la propiedad, que se basaba en la escritura inter vivos otorgada por el obispo (Pérez de Colosía, 1994: 105). Según la Real Academia Española el expolio era la adjudicación por la Corona de parte de los bienes que los obispos dejaban al morir, así como el producto de las sedes vacantes mientras no fueran cubiertas. Son beneficios que la monarquía se adjudicaba conforme al regalismo borbónico y el Concordato con la Santa Sede de 1753, que impedía que la Iglesia se apropiara de ellos, como hasta entonces.

El pleito sería perdido por los monjes del convento de Santo Domingo, por lo que los condes de Buenavista se hicieron definitivamente con la propiedad de la hacienda, que van a transformar en el jardín privado barroco más importante de España.

La escritura de donación de la hacienda al convento de Santo Domingo es muy interesante, ya que incluye datos esclarecedores. En la escritura de donación se especifica que el valor de la hacienda era superior a los quinientos sueldos, que solo supone un precio mínimo, ya que 
la propiedad debió tener un precio muy superior. La cantidad señalada debía tener alguna relación con la obligación de sacar a subasta el expolio. Según la Real Academia el sueldo era una moneda de Castilla, que equivalía a «doce dineros de a cuatro meajas». La hacienda estaba formada por una casa, huerta, viña, jardines, árboles, olivar, molinos de pan y de aceite, tierra y cortijos agregados. Uno de los autores que da más datos del Jardín Huerto, es Cristóbal Medina Conde: «Hizo la Huerta con sus estamques, varios saltadores, burladores y diferentes fuentes» (García de la Leña, 1793: 180). Más extensas son las descripciones que realiza un autor anónimo en 1814, que señala la existencia de un reloj de sol [4], una gruta cubierta de estalactitas, madréporas y corales, un depósito de agua y una calle cubierta de parras, que corresponde a la calle central, así como frutales y legumbres plantadas en los cuadros de los lados. También describe la Fuente del Delfín, la Fuente de la Batalla, y en la entrada un arco adornado con riscos, conchas y tres jarrones en la parte superior, que vierten agua en dos pilas $^{2}$. En 1907 José Moreno Villa hace la primera definición de los jardines con los nombres que actualmente posee: «La organización de los jardines es extensa y complicada, principalmente su traza puede considerarse dividida en tres partes dispuestas en plan de huerta, patio y jardín cortesano» (Moreno, 1932: 201-205).

Inicialmente era más pequeño, siendo agrandado por el obispo mediante adquisiciones, que se fueron agregando a la propiedad inicial. La donación excluye propiedades personales del obispo, tales como alhajas, muebles, pinturas y adornos de la casa. Únicamente quedan incluidos los adornos del oratorio o capilla, utilizados en la celebración del culto. Se trata de una pequeña construcción ubicada a la entrada de la plazoleta de la casa. Como compensación el convento de Santo Domingo estaba obligado a la realización de misas rezadas por las almas de sus difuntos padres ${ }^{3}$, enterrados en el altar de la capilla, y por las intenciones del propio obispo, así como la celebración de las fiestas de Santo Domingo, de Santo Tomás de Aquino y de San Ildefonso. La escritura está firmada el día 19 de julio del año 1692. El obispo se encontraba muy enfermo, pero no desahuciado, ya que los médicos le recomendaron el cambio de aires a la sierra de Ronda o de Granada. En ese momento aún no guardaba cama y solía dar largos paseos por la ribera del Guadalmedina en su silla de mano. Al parecer su fallecimien-

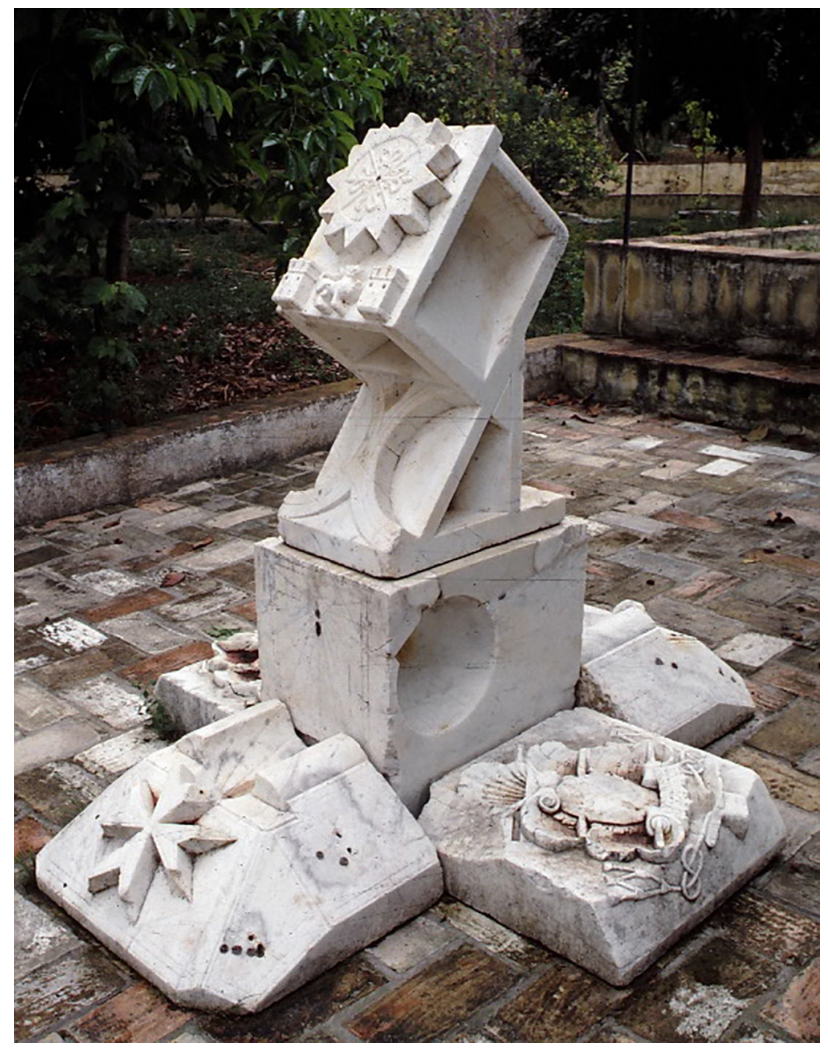

4. Reloj solar de mármol de carrara con el escudo de fray Alonso de Santo Tomás

to fue acelerado por el tratamiento de «un chímico que lo abrasó con un medicamente ardiente» 4 .

ESCRITURA DE DONACIÓN DE LA HACIENDA DE SANTO TOMÁS DEL MONTE AL CONVENTO DE SANTO DOMINGO EL REAL DE MÁLAGA POR FRAY ALONSO DE SANTO TOMÁS ${ }^{5}$

Sea notorio por esta escritura publica de donación inter vivos, pura, perfecta, e irrevocable, como Nos Don Fray Alonso de Santo Thomas, Obispo de Malaga del Consejo de su Magestad, Dezimos, que tenemos, y posseemos una hazienda de casa, guerta, viña, jardín, olivares, molinos, tierras, y cortijo en el termino de esta ciudad, que linda con la falda de la Sierra de Mijas, y otros linderos notorios, que se nombra Santo Thomas del monte, que siendo de muy corto valor adquirimos por titulo de compra, y después hemos comprado otros, que hemos agregado à dicha hazienda, y todo se comprehende en el nombre de Santo Thomas del monte. La 
qual hemos beneficiado, y aumentado con animo de hazer de ella limosna en nuestra vida à nuestro Convento de N. P. Santo Domingo de Malaga; En testimonio de amor que conservamos, por aver tomado en él el habito de este Sagrado Orden, y en él he tenido todas las graduaciones de Cathedras, y Prelacias, desde donde fuimos promovidos a la Mitra de Osma, Plasencia, y la de esta ciudad, y recíprocamente hemos experimentado los buenos oficios de dicha Religion, y Convento, dignos de remuneración. Por tanto, poniendo en execucion este nuestro antiguo, y siempre permanente justo deseo: por el tenor de la presente otorgamos, Que hacemos (como lo tenemos dicho) à el Reverendissimo Padre Prior, y Religiosos que son, y adelante fueren de este dicho Convento para siempre jamas, Donacion pura, perfecta, è irrevocable, que el derecho llama inter vivos, de la referida hazienda de Santo Thomas del monte, casa, Lagar, Guerta, Jardines, Molinos de pan, y de Azeyte, Arboles, Olivar, tierras, y Cortijos agregados, y todo quanto petenece à dicha hazienda; sin reservar en Nos cosa alguna, de que entregamos los títulos à dicho Convento, excepto las alajas, y muebles, pinturas, y todos adornos de la casa; porque nada de esto se conprehende en esta donación, sino solamente los adornos del Oratorio, y de su Capilla que son pertenecientes à dicho Oratorio, para la celebración del Culto Divino, y esta donación hazemos de nuestra libre voluntad. Por los motivos referidos, con carga de que todos los días se diga por dichos religiosos desde ahora para siempre, una Missa rezada en el Altar de la Capilla donde están depositadas las Cenizas de los señores Don Joseph de Porres Henriquez de Guzman, y Doña Costanza de Ribera y Horosco, Marqueses de Quintana, Condes de Castronovo, mis Padres; y asimismo hagan las Fiestas de N. Padre Santo Domingo, y de Santo Thomas de Aquino, y de San Ildephonso, y sean las Missas por nuestra intención, y porque perpetuamente me encomienden á Dios, y como mejor puedo, y aya lugar prometo. $Y$ me obligo, à que ningún tiempo revocaré esta donación, y á mayor abundamiento, y para mayor firmeza, Assi lo juro por el Santo Pectoral al que toco en mis manos, y en esta conformidad me desisto, y aparto del dominio, propiedad, y posesión, que tengo, y me pertenecen, y de todas, y cualesquiera acciones útiles, y directas, que me competan, y puedan competer à dicha hazienda, de que hago esta donación, y de ella otorgo cesion al dicho Prior, Convento, y Religiosos, y les hago real, y verdadera entrega de dicha hazienda, y en señal de esta voluntad entrego a dicho Convento escritura, y les concedo poder, para que luego adquieran, y tomen la possession, y en el interin seré su tenedor, y posseedor, y aunque esta donación exceda de los quinientos sueldos del derecho, sin embargo queremos tenga toda firmeza, y la aprobamos, y revalidamos quantas vezes excediere deste computo, y desde ahora la avemos por insinuada, y en caso de necesitar de mas legal, y exacta insinuación, damos facultad à dicho Prior, Convento, y Religiosos, para que la hagan en forma ante la Justicia, y renuncio las leyes, y derechos de nuestro fabor, y la general. $Y$ doy poder á el señor Nuncio de su Santidad, para que pueda en qualquier caso compelerme à el cumplimiento de esta escritura, y assi lo otorgamos en toda forma bastante, ante el infrascripto Escrivano publico, y testigos, y el Otorgante que doy fe conozco, lo firmo en la ciudad de Malaga en diez y nueve días del mes de julio de mil seiscientos y noventa y dos años, fueron testigos, Fr. Alonso, Obispo de Malaga. Estuvo presente la Comunidad al otorgamiento: aceptó, y dió las gracias. Insinuóse luego, y el día 22 se tomó la possession judicial.

\section{Notas}

1 Por el muy religioso convento de Santo Domingo el Real de la ciudad de Málaga, en el pleito con la parte de la reverenda Cámara Apostólica, Y con el defensor de los bienes del Spolio, y acreedores sobre la donación inter vivos que a dicho Real Convento hizo el llustrissimo, y Reverendissimo Señor D. Fr. Alonso de S. Tomas. Obispo de Malaga de fel. mem. En Málaga lo imprimió Mateo López Hidalgo. Año de 1693, p. 4.

2 A.M.S. (1814), Descripción de la casa de campo del Retiro, del conde de Villalcázar. Málaga, Impreso en la oficina de don Luis de Carreras, p. 97.

3 Según consta en la escritura de donación los padres legales del obispo estaban enterrados en el altar de la capilla de la hacienda: don José de Porres Henríquez de Guzmán y doña Constanza de Ribera y Horozco, marqueses de Quintana y condes de Castronovo. Doña Constanza era la dama de la reina, con la que se supone que Felipe IV tuvo uno de sus hijos naturales, fray Alonso de Santo Tomás, y a la que casaron con el marqués de Quintana, residente en la población de Vélez Málaga.

4 Archivo Histórico Provincial de Málaga, Leg. 2200, Escribanía de Mateos Villazo, fols. 420r-420v.

5 Por el muy religioso..., (1693), p. 22. 


\section{Bibliografía}

A.M.S. (1814), Descripción de la casa de campo del Retiro, del conde de Villalcázar, Impreso en la oficina de don Luis de Carreras, Málaga. CAMACHO MARTíNEZ, Rosario (1996), Descripción de la casa de campo del Retiro del Conde de Villalcázar, Real Academia de Bellas Artes de San Telmo, Málaga. Reproducción de la edición de Málaga de 1814.

CHUECA GOITIA, Fernando y TEMBOURY ÁLVAREZ, Juan (1947), «José Martín de Aldehuela y sus obras en Málaga. Palacios y Jardines», Arte Español, pp. 7-19.

GARCÍA DE LA LEÑA, Cecilio (1793), Conversaciones Históricas Malagueñas, vol. IV. Edición facsímil de la Caja de Ahorros Provincial de Málaga, Málaga, 1981.

MORALES FOLGUERA, José Miguel (coord.) (1994a), Fray Alonso de Santo Tomás y la Hacienda El Retiro, Benedito Editores, Málaga.

- (1994b), «Empresas artísticas», en Fray Alonso de Santo Tomás y la Hacienda El Retiro, Benedito Editores, Málaga, pp. $199-298$.

- (1996), Los jardines históricos de El Retiro, Benedito Editores, Málaga.

MORENO VILLA, José (1932), «Jardines malagueños», Revista Arquitectura, n. 159, pp. 201-205.

PÉREZ DE COLOSÍA, M. ${ }^{a}$ Isabel (1994), «Un personaje del Barroco», en MORALES FOLGUERA, José Miguel (coord.), Fray Alonso de Santo Tomás y la Hacienda El Retiro, Benedito Editores, Málaga, pp. 11-114.

PETERS, F. E. (1985), Jerusalem, Princeton University Press, New Jersey.

PONZ, Antonio (1794), Viage de España, tomo XVIII, Madrid.

Por el muy religioso convento de Santo Domingo el Real de la ciudad de Málaga, en el pleito con la parte de la reverenda Cámara Apostólica, Y con el defensor de los bienes del Spolio, y acreedores sobre la donación inter vivos que a dicho Real Convento hizo el Ilustrissimo, y Reverendissimo Señor D. Fr. Alonso de S. Tomas. Obispo de Malaga de fel. mem. En Málaga lo imprimió Mateo López Hidalgo. Año de 1693. Archivo de la Real Academia de la Historia de Madrid.

SANTOS ARREBOLA, M. ${ }^{a}$ Soledad (1989), "La finca del Retiro: la herencia cuestionada de fray Alonso de Santo Tomás», Jábega, n. ${ }^{\circ 66}$, pp. 16-20.

TEMBOURY ÁlVAREZ, Juan y CHUECA GOITIA, Fernando (1974), «José Martín de Aldehuela y sus obras en Málaga», Informes Histórico Artísticos, tomo I, Caja de Ahorros Provincial de Málaga, Málaga, pp. 70-85. 